\section{Before and after major neck surgery}

\author{
Stefano Della Villa
}

\section{SPORTY BEGINNINGS}

I have always loved sport, and I entered into the sports medicine environment for this reason. During my life I have enjoyed swimming, skiing, running, tennis and football, and I have always tried to fit as many of these activities around my family and work commitments as possible.

From a career perspective I was lucky enough to work with the San Francisco 49 ers at a young age, before having a wonderful experience working as a sports physician in a Bologna during the next stage of my career. The biggest joy of my professional life was bringing the football medicine community together in recent years via the isokinetic conferences. In short, I love sport and it has played a major part in my life.

\section{DOCTOR-TURNED-PATIENT}

I was very fortunate in that for a long time I had never experienced anything close to a serious pathology. I remember feeling surprised when I was first diagnosed with my neck symptoms-how was it possible that an 'unbreakable man' like me could have such pain? Eventually I came to humbly understand that I was a normal human being, as vulnerable and as capable of being injured as all the patients that I had seen during my working life.

Following an MRI, I received the diagnosis of triple cervical disc herniation with an EMG showing that my nerve roots were not in a good way. For me, these findings were when the penny dropped and I grasped the severity of my situation: I was becoming a patient.

Despite this realisation, I did everything I could to avoid surgery and for 1 month adhered to an intensive conservative treatment regime. However, this was unsuccessful and when I couldn't lift a cup of coffee with my right hand, I finally accepted that surgery was necessary.

\section{SOCIAL SUPPORT}

The people around me have been fantastic and have themselves been a very powerful medicine. I learnt for the first time the real

Correspondence to Dr Stefano Della Villa, Education Research Department, Isokinetic Medical Group, Bologna 40132, Italy; s.dellavilla@isokinetic.com

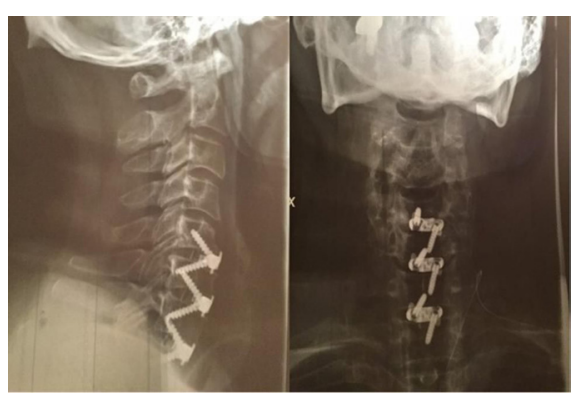

Figure 1 Postoperative images following triple cervical fusion.

meaning of the word 'solidarity'. It might sound strange, but you need to be weak in order to completely understand the power of your support network.

Working as a doctor often puts us in a dominant situation and it is only when we are a patient, suffering very much, that we can better understand how we need the support of others. I'm not just speaking about the practical issues, like having somebody to drive the car, I'm speaking about the emotions, the love, the friendship. You can find a lot of positive energy around you.

\section{THE OPERATION ITSELF}

My surgeon (Pedro Berjano) is also my friend but he acted in a very professional way with me, giving me time to try the

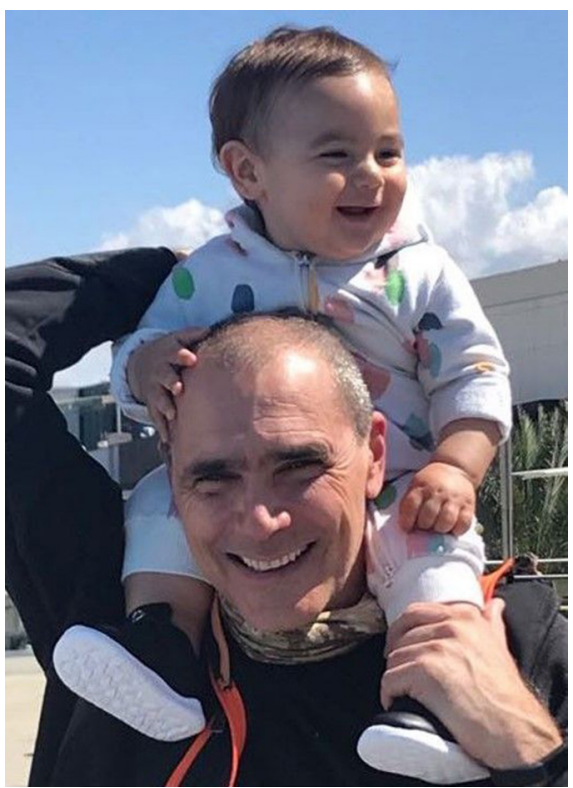

Figure 2 With my grandson 3 months post surgery (neck muscles healing well). conservative approach before I decided to go for the surgical route. When he described the triple fusion procedure, and it was a tough moment for me. I visualised my neck open, with all the tools needed to reach the anterior part of my cervical spine.

My medical background was not helpful to me just before the surgery, when the anaesthesiologist explained to me the risks associated with the surgery and the anaesthesia. As a doctor, you present all the potential complications to patients with a great awareness, but without an emotional attachment. As a patient though, you can feel an emotional reaction to any single word. In my case, being both a doctor and a patient, I could give a probability of each single complication, so I started to think: OK the chances are one in a thousand but I could be the one....

\section{AFTER THE SURGERY}

Immediately after the surgery, I was a different person compared with before the operation. My initial feeling in the recovery room was 'I'm alive', and it was a wonderful feeling. And I was delighted because my arm pain had immediately disappeared. I felt well and refreshed, maybe also thanks to the combination of medications used during and after the surgery (figure 1 ).

A few days later at home I found things much harder. I had to wear a collar brace, I felt sore in even simple movements, I felt very weak and I needed help with even simple daily activities. This showed me that being a patient means to have a lot of patience. You have to be tolerant, to reduce your speed, to accept your new situation. It was like reducing the intensity of my life by a factor of 10 .

Having goals to aim for were essential to overcome that period of my recovery. At the age of 58 years my goals were to try to get back to the shape I used to be in order to live an active life, to be able to play non-contact sports, and more important to play with my growing grandchild (figure 2).

\section{FUTURE CONCERNS AND OUTLOOK}

I now have a far greater awareness of myself. I don't know what my future range of motion will be in my neck, and how much this potential impairment will affect my life. I'm also anxious as to which part of my body might fail in the future, and I'm aware that at my age it's possible to face other situations like this one. I feel that a good maintenance regime is crucial 
for my future health and so I will work less, I will give more time for me, and I'll give more time to do more prevention exercises.

\section{THREE BITS OF ADVICE FOR} CLINICIANS (PHYSIOTHERAPISTS AND DOCTORS) WORKING WITH PATIENTS PRIOR TO OR FOLLOWING MAJOR

\section{NECK SURGERY?}

1. After a correct diagnosis, have a precise plan of treatment. For example, a few weeks of conservative approach and then preparing for surgery, if their muscles continue to lose strength and function.
2. Just after the surgery, explain to the patient very clearly about the things to do in the next few weeks. The main things I found useful to know were the use of the collar, the feeling of a rigid neck, the pain when sleeping, the healing of the wound and the need to walk a couple of hours a day to feel better.

3. Start the rehabilitation at the right time and avoid anything that might jeopardise the healing of the operation. Be very careful and progressive and try to help the patient to improve self-confidence because the recovery starts always from the mind and then within the body.
Correction notice This article has been corrected since it published Online First. The title has been updated.

Competing interests None declared.

Patient consent Not required.

Provenance and peer review Not commissioned; internally peer reviewed.

(c) Author(s) (or their employer(s)) 2019. No commercial re-use. See rights and permissions. Published by BMJ.

\section{D) Check for updates}

To cite Della Villa S. Br J Sports Med 2019;53:1565-1566.

Accepted 29 October 2018

Published Online First 5 December 2018

Br J Sports Med 2019;53:1565-1566. doi:10.1136/bjsports-2018-100247 